\title{
Activin A Plasma Levels at Birth: An Index of Fetal Hypoxia in Preterm Newborn
}

\author{
PASQUALE FLORIO, SERAFINA PERRONE, STEFANO LUISI, MARIANGELA LONGINI, \\ DONATELLA TANGANELLI, FELICE PETRAGLIA, AND GIUSEPPE BUONOCORE
}

Department of Pediatrics, Obstetrics and Reproductive Medicine, University of Siena, 53100 Siena, Italy

\begin{abstract}
ABST
Activin-A is a growth factor involved in cell growth and
differentiation, neuronal survival, early embrionic development
and erythropoiesis. Hypoxemia is a specific trigger for increasing
activin-A in fetal lamb circulation. We tested the hypothesis that
fetal hypoxia induces activin-A secretion in preterm newborn
infants. Fifty newborn infants with gestational ages ranging from
26 to 36 wk were enrolled in a prospective study performed at the
Pediatrics, Obstetrics and Reproductive Medicine Department,
University of Siena, Italy. Heparinized blood samples were
obtained from the umbilical vein after cord clamping, immedi-
ately after delivery. Activin A, hypoxanthine (Hx), xanthine (Xa)
plasma levels and absolute nucleated red blood cell (NRBC)
count were measured. Activin-A levels ( $p<0.0001)$ and NRBC
( $p<0.0001)$ were significantly higher in hypoxic than in non
\end{abstract}
Activin $\mathrm{A}$ is a growth factor $(\beta \mathrm{A} / \beta \mathrm{A}$ dimer $)$ mainly produced by the placenta, decidua and fetal membranes and secreted in large amounts in maternal circulation (1-7). Inhibin/activin subunits are expressed in a variety of tissues, including ovary, testis, placenta, adrenal, kidney, brain and pituitary gland. Inhibin A and Activin A have been reported to regulate various physiologic functions, including $\mathrm{ACTH}$ and GH secretion, neuronal survival, hypothalamic oxytocin secretion, erythropoiesis, early embryonic development and gonad function (8-11). Activin A concentrations significantly increase in maternal serum with advancing gestation (12), whereas umbilical cord blood serum do not significantly differ from midpregnancy to term gestation (7) and are significantly lower than in maternal serum $(6,7)$. Disorders of pregnancy due to reduced placental perfusion and various degrees of

Received December 12, 2002; accepted April 17, 2003

Correspondence: Prof. Giuseppe Buonocore, MD, Department of Pediatrics, Obstetrics and Reproductive Medicine, University of Siena, Policlinico "Le Scotte", V.le Bracci 36, 53100 Siena, Italy; e-mail: buonocore@unisi.it

Grants from the Italian Ministry for the University and Scientific-Technological Research (MIUR 2001: "Identification of etiopathogenetic factors characteristics of newborn at high risk of brain damage in perinatal period. Clinical and experimental study") and from the University of Siena, Italy (Piano d'Ateneo per la Ricerca 2001: "Predictive value of hormones/growth factors measurements in feto-maternal diseases").

Authors did not have any financial arrangements or other factors which could compromise the objectivity of the research.

DOI: 10.1203/01.PDR.0000086905.71963.1D hypoxic preterm newborns. Cord activin A levels were significantly related with $\mathrm{Hx}\left(\tau_{\mathrm{a}}=0.64, \tau_{\mathrm{b}}=0.64, p<0.0001\right)$ and $\mathrm{Xa}$ $\left(\tau_{\mathrm{a}}=0.56, \tau_{\mathrm{b}}=0.57, p<0.0001\right)$ levels, NRBC $\left(\left(\tau_{\mathrm{a}}=-0.45\right.\right.$, $\left.\tau_{\mathrm{b}}=-0.46, p<0.0001\right)$ count; $\mathrm{pH}\left(\tau_{\mathrm{a}}=-0.47, \tau_{\mathrm{b}}=-0.48, p<\right.$ $0.0001)$ and base deficit $\left(\tau_{\mathrm{a}}=-0.36, \tau_{\mathrm{b}}=0 .-0.36, p=0.0002\right)$. Preterm newborns with signs of perinatal hypoxia at birth have increased activin-A levels, suggesting that activin-A may reflect indirectly intrauterine hypoxia. (Pediatr Res 54: 696-700, 2003)
Hx, hypoxanthine
Abbreviations
Xa, xanthine
NRBC, nucleated red blood cell
$\tau$, Kendall's rank correlation coefficient tau

feto-placental hypoxemia, such as preeclampsia and fetal growth restriction (13) are characterized by increased levels of maternal and umbilical cord activin A (12), and feto-placental and/or maternal isocapnic hypoxemia are specific triggers for an increase in activin A. Indeed, cord blood Activin A levels increase in the sheep after induction of hypoxia, remain elevated throughout hypoxia and return to control values when normal blood flow is restored (14). Activin A subunit mRNA expression is up-regulated during hypoxic ischemia in the adult brain and cerebral hypoxia stimulates Activin A secretion in rat newborns as well as in adult animals $(15,16)$. No human study to date has determined whether this protein is altered in babies with clinical signs of hypoxia at birth. Perinatal hypoxia set in motion a cascade of biochemical events commencing with a shift from oxidative to anaerobic metabolism, which leads to a rapid rise in the levels of lactic acid and of oxygen free radicals (17). During hypoxia the cutback in oxidative phosphorilation rapidly diminishes reservers of high-energy phopshate. High levels of adenosine and hypoxanthine accumulate in a few minutes $(18,19)$. The breakdown of hypoxanthine by xanthine oxidase in the presence of oxygen produces a flood of superoxide radicals. Several experimental studies have demonstrated a direct relation between the degree of hypoxia and the severity of oxidative damage due to free radicals production during hypoxia in fetal life $(20-22)$. 
We recently demonstrated a hypoxia-induced increase in nucleated red blood cell (NRBC) count at birth and its predictive value for neurodevelopmental outcome (23). We suggested that hypoxia and perinatal distress are the two main factors responsible for increasing NRBC counts by stimulating erythropoietin production.

It has been proposed that activin secretion increases when there is neonatal cerebral hypoxemia (15), giving rise in erythropoietin-induced stimulation of hematopoiesis $(24,25)$. We tested the hypothesis that activin A plasma levels increase in preterm newborn infants with fetal tissue hypoxia.

\section{MATERIALS AND METHODS}

Subjects. Fifty preterm newborn babies with gestational age 26-36 wk (for more details see Table 1), consecutively admitted to the Neonatology Division of Siena, University Hospital, were enrolled in the study. All babies with congenital malformations, inborn errors of metabolism, blood group incompatibility, sepsis, diabetic mothers, multiple gestation, and those not born in the clinic were excluded. Perinatal hypoxia was defined as the presence of at least two of the following conditions: intrapartum distress, as indicated by fetal bradycardia with a heart rate of less than 100 beats per minute, late decelerations, or an absence of heart rate variability; an Apgar score of 6 or less at five minutes; a need for resuscitation for more than one minute with positive-pressure ventilation and oxygen immediately after birth; a pH value of 7.20 or less in umbilical vein $(22,23,26,27)$. Twenty six of the 50 newborns were regarded as hypoxic. Eleven of 26 hypoxic babies were reanalyzed separately to verify whether stricter criteria of hypoxia ( $\mathrm{pH}<7.10$ in umbilical vein, Apgar score $<5$ at 5 min) changed our results. Twenty four babies, without signs of perinatal hypoxia were used as control subjects. The degree of hypoxia was ascertained by determination of hypoxanthine (Hx) and xanthine (Xa) concentrations in cord blood. The study was masked throughout. It was approved by the Human Ethics Committee of the Medical Faculty, University of Siena. Informed written parental consent was obtained before enrolment of each infant.

Methods. Heparinized blood samples were obtained from the umbilical vein after cord clamping, immediately after delivery. A complete blood cell count was performed, and total white blood cell count was determined. NRBC count was expressed as the absolute erythroblast count $\left(\mathrm{NRBC} / \mathrm{mm}^{3}\right)$, obtained by light microscopic examination of May-GrunwaldGiemsa-stained blood smears. Blood gas analysis was measured with a model ABL 505 analyzer (Radiometer, Copenaghen, Denmark) immediately after blood sampling. The blood was centrifuged and analysis of $\mathrm{Hx}, \mathrm{Xa}$ and activin A was carried out in plasma within $2 \mathrm{~h}$ of blood sampling to avoid storage effects. After centrifuging, the plasma and buffy coat were removed. Hx and Xa plasma levels were evaluated by HPLC, using a Varian Vista 5500 high-performance liquid chromatograph equipped with a variable-wavelength UV detector (model 4290, Varian, Palo Alto, CA, U.S.A.) (22). A ready-to-use prepacked column Supelcosil LC-18 column by Supelco $(250 \times 4.6 \mathrm{~mm}$ internal diameter, $5 \mu \mathrm{m})$, with precolumn $(20 \times 4.6 \mathrm{~mm}$ internal diameter $)$ filled with the same packing (Supelguard, Supelco, St. Louis, MO, U.S.A.) completed the analytical system. The mobile phase gradient used was: time $0 \min (\mathrm{A}=100 \%, \mathrm{~B}=0 \%)$, time $10 \min (\mathrm{A}=90 \%$, $\mathrm{B}=10 \%)$, time $20 \min (\mathrm{A}=80 \%, \mathrm{~B}=20 \%)$, time $30 \min (\mathrm{A}$ $=100 \%, \mathrm{~B}=0 \%$ ), with $\mathrm{A}$ was $10^{-2} \mathrm{M}$ potassium phosphate buffer at $\mathrm{pH} 5.5$ and $\mathrm{B}$ was methanol. The next sample was injected after an interval of $10 \mathrm{~min}$. The flow rate was 1 $\mathrm{mL} / \mathrm{min}$ and the wavelength $220 \mathrm{~nm}$. The detection limits for $\mathrm{Hx}$ and $\mathrm{Xa}$ were $0.06 \mu \mathrm{g} / \mathrm{mL}$ and $0.2 \mu \mathrm{g} / \mathrm{mL}$ respectively

Activin A concentrations were measured using specific twosite enzyme immunoassays (Serotec, Oxford, UK), as previously described (28). Briefly, plates were washed and bound

Table 1. Clinical characteristics of newborns

\begin{tabular}{|c|c|c|c|}
\hline Newborns $(n)$ & Hypoxic $(n=26)$ & Nonhypoxic $(n=24)$ & $p$ Value \\
\hline Gestational age (wk)* & $30.7 \pm 3.9(27-38)$ & $32.3 \pm 3.9(27-36)$ & NS \\
\hline Gender & 10 male, 16 female & 14 male, 10 female & NS \\
\hline 1-Min Apgar score* & $3.5 \pm 2.2(1-7)$ & $7.7 \pm 2.5(3-10)$ & 0.002 \\
\hline \multicolumn{4}{|l|}{ Delivery } \\
\hline Vaginal delivery & 19 & 18 & NS \\
\hline Cesarean section & 7 & 6 & NS \\
\hline Abruptio placentae & 1 & 0 & \\
\hline $\begin{array}{l}\text { Extensive placental infarction }(>5 \\
\mathrm{cm} \text { in diameter or multiple lesions } \\
>2 \mathrm{~cm} \text { in diameter })\end{array}$ & 8 & 9 & NS \\
\hline \multicolumn{4}{|l|}{ Blood gas analysis } \\
\hline $\mathrm{pH}^{*}$ & $7.09 \pm 0.12(6.98-7.22)$ & $7.32 \pm 0.03(7.29-7.36)$ & $<0.0001$ \\
\hline
\end{tabular}

Perinatal hypoxia was defined as the presence of at least two of the following conditions: intrapartum distress, as indicated by fetal bradycardia with a heart rate of $<100$ beats per minute, late decelerations, or an absence of heart rate variability; an Apgar score of $\leq 6$ at 5 min; a need for resuscitation for $>1$ min with positive-pressure ventilation and oxygen immediately after birth; a $\mathrm{pH}$ value of $\leq 7.20$ in umbilical vein.

* Plus-minus values are mean $\pm \mathrm{SD} ; 10$ th and 90 th percentile in brackets. 
alkaline phosphatase was quantified using a commercially available enzyme immunoassay amplification system (Immuno Select ELISA Amplification System, Dako, Milan, Italy), according to the manifacturer's instructions.

The analytical detection limit of the activin A assay was less than $100 \mathrm{pg} / \mathrm{mL}$; intra-and inter-assay coefficients of variation were $5.0 \%$ and $9.0 \%$, respectively. Cross-reactions for each assay with the various inhibin-related proteins were less than $0.5 \%$. Activin A plates were read at $490 \mathrm{~nm}$ on an automated ELISA plate reader (Basic Radim Immunoassay Operator, Radim spa, Pomezia, Italy).

Statistical analysis. The data, expressed as means \pm SD, median and $10^{\text {th }}$ and $90^{\text {th }}$ percentile, were analyzed for statistically significant differences by Mann-Whitney $U$ non parametric test for continuous data and by Fisher's exact test for categorical data. Kendall's rank correlation coefficient was used to asses linkages between variables. Statistical analysis was performed using Stata $8{ }^{\circledR}$ (Stata Corp.-4905 Lakeway Drive- College Station, TX 77845 USA)

\section{RESULTS}

No differences in gestational age and birth weight between hypoxic and non hypoxic babies were found, but newborns with signs of perinatal hypoxia had significantly lower $\mathrm{pH}$ $(\mathrm{P}<0,0001)$, higher base deficit levels $(p<0.0001)$, higher $\mathrm{pCO}_{2}(\mathrm{P}=0,01)$ and lower $\mathrm{pO}_{2}$ levels $(\mathrm{P}=0,03)$ than non hypoxic neonates. (Table 1 )

As expected, hypoxic newborns showed significantly higher plasma levels of Hx, Xa and NRBC count than non hypoxic neonates (Table 2).

Activin A levels were significantly higher in hypoxic than non hypoxic newborns (medians, minimum and maximum values: $2.2 ; 5.4-0.5$ versus $0.5 ; 1.7-0.2 \mathrm{ng} / \mathrm{mL}, p<0.0001$ ).

There were no difference in clinical characteristics: maternal age, parity, race, gestational age, gender, birth weight, mode of delivery, and placental pathologies the two groups. Similar results, were found in 11 out of 26 hypoxic babies meeting stricter criteria of hypoxia with respect to non hypoxic babies (Table 2)

Cord activin A levels were significantly related with $\mathrm{Hx}$ $\left(\tau_{\mathrm{a}}=0.64, \tau_{\mathrm{b}}=0.64, p<0.0001\right)$ and $\mathrm{Xa}\left(\tau_{\mathrm{a}}=0.56, \tau_{\mathrm{b}}=0.57, p\right.$ $<0.0001)$ levels (Fig. 1A and Fig. 1B), $\mathrm{pH}\left(\tau_{\mathrm{a}}=-0.47, \tau_{\mathrm{b}}=-\right.$ $0.48, p<0.0001)$ (Fig. 2A) and base deficit $\left(\tau_{\mathrm{a}}=-0.36, \tau_{\mathrm{b}}=0\right.$.$0.36, p=0.0002)$ (Fig. 2B), and NRBC $\left(\tau_{\mathrm{a}}=-0.45, \tau_{\mathrm{b}}=-0.46\right.$, $p<0.0001$ ) (Fig. 3).

\section{DISCUSSION}

The present study first refers on activin A and hypoxia in humans: newborns with clinical signs of perinatal hypoxia had
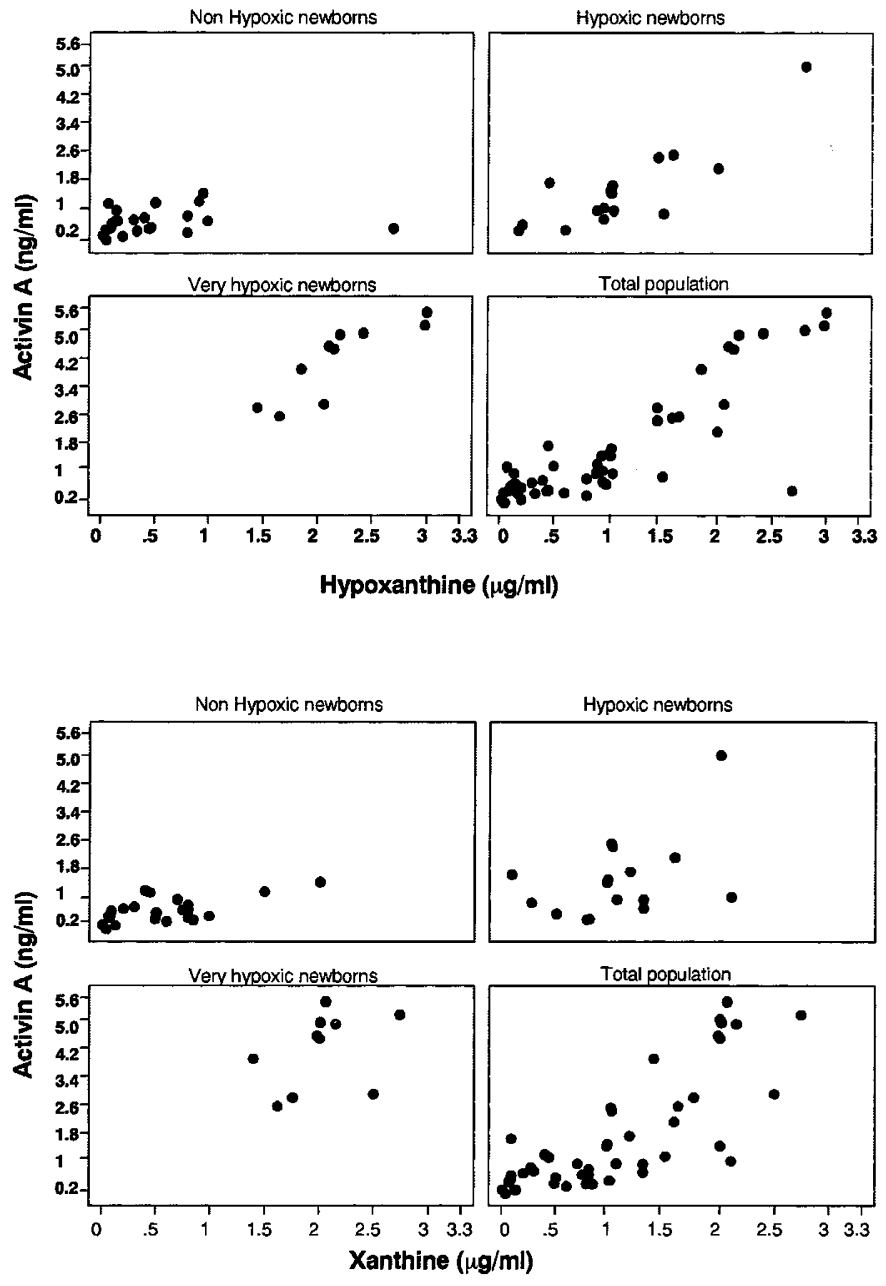

Figure 1. A: Correlations between cord plasma levels of activin A and hypoxanthine. B: Correlations between cord plasma levels of activin A and xanthine.

higher activin A levels, which were correlated with biochemical features of hypoxia such as higher NRBCs and plasma Hx and $\mathrm{Xa}$ levels, as well as lower $\mathrm{pH}$ and higher base deficit levels, confirming previous our reported findings $(22,27)$ and suggesting that hypoxia is a trigger to stimulate activin A secretion. In line with this suggestion is the fact that intrauterine fetal death, a condition due to fetal hypoxia, is characterized by higher activin A levels in amniotic fluid (29), and that the feto-placental and/or maternal isocapnic hypoxemia increase activin A secretion in fetal lamb circulation until the hypoxic stimuli is removed (14).

With respect to the source of this rise of activin A in cord blood of hypoxic neonates, increased expression of activin subunit proteins (30) has been described in placentas of preg-

Table 2. Cord plasma levels (medians, minimum, and maximum values) of hypoxanthine, xanthine, NRBC, and activin A in nonhypoxic, moderately hypoxic, and very hypoxic babies

\begin{tabular}{|c|c|c|c|c|c|c|}
\hline & $\begin{array}{c}\text { Nonhypoxic } \\
\text { (A) }\end{array}$ & $\begin{array}{c}p \text { Value } \\
\mathrm{A} v s \mathrm{~B}\end{array}$ & Moderately hypoxic (B) & $\begin{array}{l}p \text { Value } \\
\mathrm{B} \text { vs } \mathrm{C}\end{array}$ & Very hypoxic (C) & $\begin{array}{l}p \text { Value } \\
\text { A vs C }\end{array}$ \\
\hline $\mathrm{Hx}(\mu \mathrm{g} / \mathrm{mL})$ & $0.2(0-2.6)$ & 0.0002 & $1.0(0.2-2.8)$ & 0.0005 & $2.1(1.4-3.0)$ & $<0.0001$ \\
\hline $\mathrm{Xa}(\mu \mathrm{g} / \mathrm{mL})$ & $0.5(0-2.0)$ & 0.0019 & $1.0(0.1-2.1)$ & 0.0004 & $2.0(1.4-2.7)$ & $<0.0001$ \\
\hline $\mathrm{NRBC}\left(\times \mathrm{mm}^{3}\right)$ & $394.5(0-3,196)$ & 0.0021 & $2,601.5(0-9,500)$ & 0.0014 & $9,045.0(3,748-10,334)$ & $<0.0001$ \\
\hline Activin A (ng/mL) & $0.5(0.1-1.4)$ & 0.0011 & $1.22(0.4-5.0)$ & 0.0001 & $4.5(2.6-5.5)$ & $<0.0001$ \\
\hline
\end{tabular}



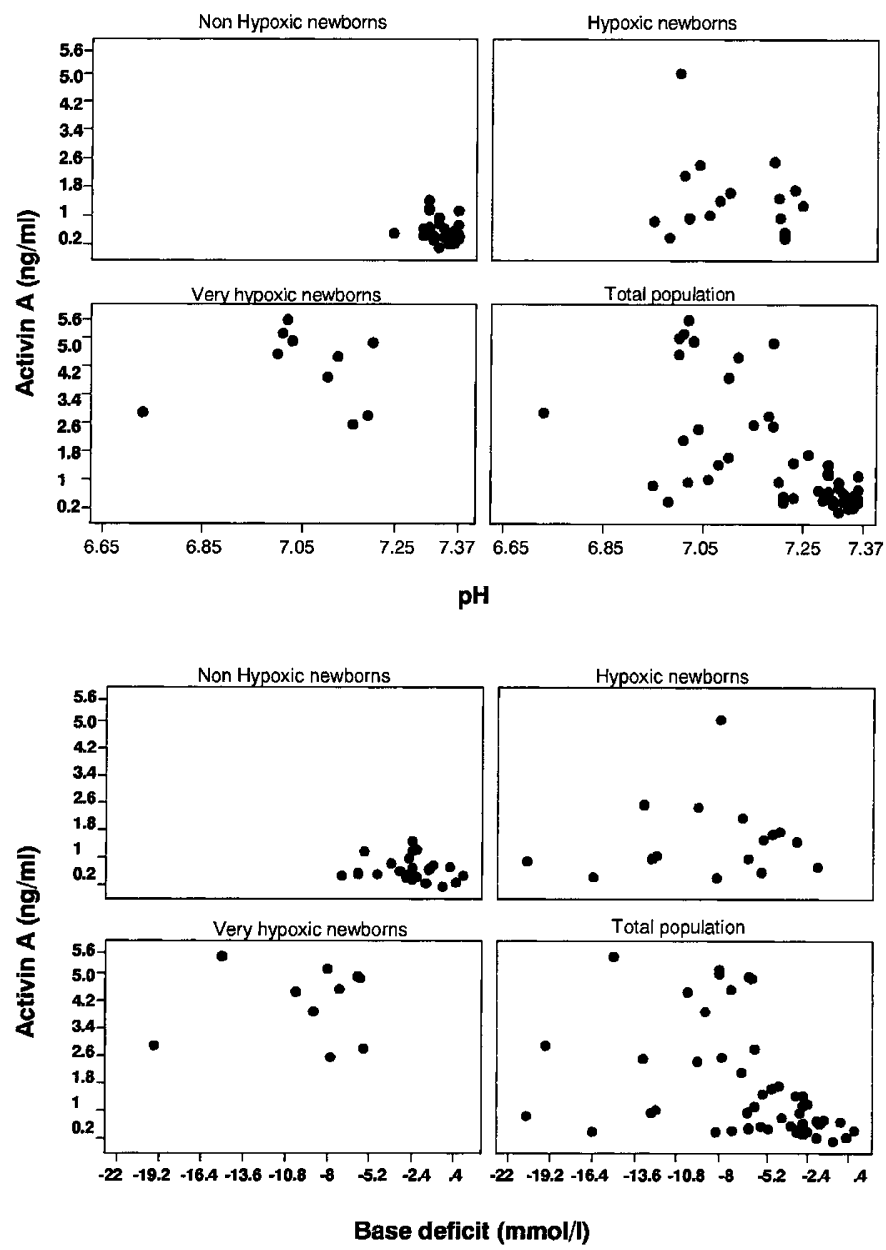

Figure 2. A: Correlations between cord plasma levels of activin A and pH. B: Correlations between cord plasma levels of activin A and base deficit.

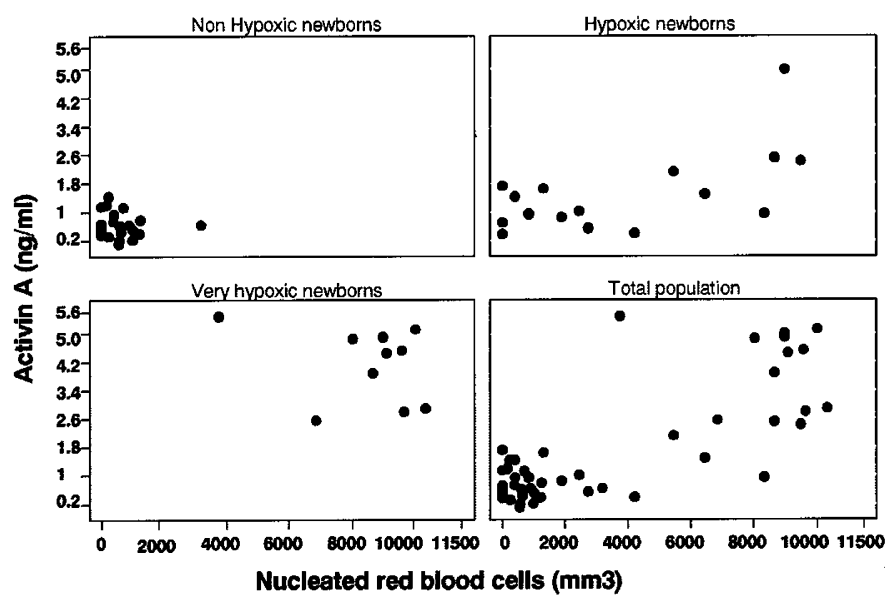

Figure 3. Correlation between cord plasma levels of activin A and NRBC.

nant women with preeclampsia or fetal growth restriction, suggesting that increased levels of activin A in hypoxic newborns may partially be due to increased placental expression and synthesis. However, recent in vitro data revealed that hypoxia significantly reduced synthesis and secretion of activin A by the human placenta $(31,32)$. The data obtained in fetal lambs and our results suggest that the increased levels of activin A in fetal blood arise from the fetus and that a significant relationship exist between this increase and fetal hypoxia

Fetal and neonatal hypoxia is followed by severe changes in erythropoiesis and red cell characteristics (33), through production of erythropoietin (34). Interestingly, activin A augments erythropoietin-induced stimulation of hematopoiesis $(24,25,35)$, and directly regulates erythropoiesis (36). The relationship observed between activin A levels and hypoxanthine and xanthine concentrations strongly suggests that hypoxia induces activn A release. The correlation found between activin A and NRBC suggests hypoxia is one of common stimulus for increased erythropoiesis and activin A release. Increased activin A levels in cord blood of hypoxic newborns may also be a further direct trigger to hematopoiesis in the depressed fetus. Since distinct NRBC patterns seem to be related to the timing of fetal neurologic impairment $(23,37-$ 40), the relationship between activin A and NRBC suggests activin $\mathrm{A}$ as a possible indicator of fetal injury at birth.

\section{CONCLUSION}

In conclusion, intrauterine hypoxia is one of the common factors responsible for increasing activin A levels in fetal circulation. The high correlation of activin A with clinical and biochemical signs of fetal and neonatal hypoxia lead us to suggest that activin $\mathrm{A}$ is a possible indicator of intrauterine hypoxia.

Acknowledgment. The authors thank Dr. Piero Vezzosi for skillful assistance in statistical analysis.

\section{REFERENCES}

1. Petraglia F, Sawechenko P, Lim ATW, Vale W 1987 Localization, secretion and action of inhibin in human placenta. Science 237:189-192

2. Petraglia F, Garuti GC, Calzà L, Roberts V, Giardino L, Genazzani AR, Vale W, Meunier H 1991 Inhibin subunits in human placenta: localization and messenger ribonucleic acid levels during pregnancy. Am J Obstet Gynecol 165:750-758

3. Petraglia F, Florio P, Nappi C, Genazzani AR 1996 Peptide signaling in human placenta and membranes autocrine, paracrine, and endocrine mechanisms. Endocr Rev 17:156-181

4. Petraglia F, De Vita D, Gallinelli A, Aguzzoli L, Genazzani AR, Romero R, Woodruff TK 1995 Abnormal concentration of maternal serum activin-A in gestational diseases. J Clin Endocrinol Metab 80:558-561

5. Muttukrishna S, Fowler PA, George L, Groome NP, Knight PG 1996 Changes in peripheral serum levels of total activin A during the human menstrual cycle and pregnancy. J Clin Endocrinol Metab 81:3328-3334

6. Florio P, Benedetto C, Luisi S, Santuz M, Di Carlo C, Marozio L, Genazzani AR, Petraglia F 1999 Activin A, inhibin A, inhibin B and parturition: changes of maternal serum and cord levels according to the mode of delivery. Br J Obstet Gynecol 106:1061-1065

7. Debieve F, Beerlandt S, Hubinont C, Thomas K 2000 Gonadotropins, prolactin, inhibin $\mathrm{A}$, inhibin $\mathrm{B}$, and activin $\mathrm{A}$ in human fetal serum from midpregnancy and term pregnancy. J Clin Endocrinol Metab 85:270-274

8. Iwahori Y, Saito H, Torii K, Nishiyama N 1997 Activin exerts a neurotrophic effect on cultured hippocampal neurons. Brain Res 760:52-58

9. Mesiano S, Jaffe RB 1997 Role of growth factors in the development regulation of the human adrenal cortex. Steroids 62:62-72

10. Lovell TM, Gladwell RT, Groome NP, Knight PG 2002 Differential effects of activin A on basal and gonadotrophin-induced secretion of inhibin A and progesterone by granulose cells from preovulatory (F1- F3) chicken follicles. Reproduction 124:649657

11. Welt C, Sidis Y, Keutmann H, Schneyer A 2002 Activins, inhibins and follistatins: from endocrinology to signaling. A paradigm for the new millennium. Exp Biol Med 227:724-752

12. Florio P, Cobellis L, Luisi S, Ciarmela P, Severi FM, Bocchi C, Petraglia F 2001 Changes in inhibins and activin secretion in healthy and pathological pregnancies. Mol Cell Endocrinol 180:123-130

13. Roberts JM, Cooper DW 2001 Pathogenesis and genetics of pre-eclampsia. Lancet 357:53-56 
14. Jenkin G, Ward J, Hooper S, O'Connor A, de Kretser D, Wallace E 2001 Fetoplacental hypoxemia regulates the release of fetal activin A and prostaglandin $\mathrm{E}(2)$ Endocrinology 142:963-966

15. Wu DD, Lai M, Hughes PE, Sirimanne E, Gluckman PD, Williams CE 1999 Expression of the activin axis and neuronal rescue effects of recombinant activin A following hypoxic-ischemic brain injury in the infant rat. Brain Res 835:369-378

16. Lai M, Sirimanne E, Williams CE, Gluckman PD 1996 Sequential patterns of inhibin subunit gene expression following hypoxic-ischemic injury in the rat brain. Neuroscience 70:1013-1024

17. Saugstad OD 1996 Mechanisms of tissue injury by oxygen radicals: implications fo neonatal disease. Acta Paediatr 85:1-4

18. Saugstad OD, Gluck L 1982 Plasma hypoxanthine levels in newborn infants: a specific indicator of hypoxia. J Perinatal Med 10:266-272

19. Saudgstad OD 1975 Hypoxanthine as a measurement of hypoxia. Pediatr Res $9: 158-161$

20. Mishra OP, Delivoria-Papadopoulos M 1989 Lipid peroxidation in developing fetal guinea pig brain during normoxia and hypoxia. Dev Brain Res 45:129-135

21. Delivoria-Papadopoulos M, Mishra OP 1998 Mechanisms of cerebral injury in perinatal asphyxia and strategies for prevention. J Pediatr 132:S30-S34

22. Buonocore G, Perrone S, Longini M, Vezzosi P, Bracci R 2000 Total hydroperoxide and advanced oxidation protein products in preterm hypoxic babies. Pediatr Res 47:221-224

23. Buonocore G, Perrone S, Gioia D, Gatti MG, Massafra C, Agosta R, Bracci R 1999 Nucleated red blood cell count at birth as an index of perinatal brain damage. Am J Obstet Gynecol 181:1500-1505

24. Broxmeyer HE, Lu L, Cooper S, Schwall Rh, Mason AJ, Nikolics K 1988 Selective and indirect modulation of human multipotential and erythroid hematopoietic progenitor cell proliferation by recombinant human activin and inhibin. Proc Natl Acad Sci U S A 85:9052-9056

25. Yu J, Shao L, Vaughan J, Vale W, Yu AL 1989 Characterization of the potentiation effect of activin on human erythroid colony formation in vitro. Blood 73:952-960

26. Buonocore G, Zani S, Perrone S, Caciotti B, Bracci R 1998 Intraerytrocyte nonprotein-bound iron and plasma malondialdehyde in the hypoxic newborn. Free Radic Biol Med 25:770-776

27. Buonocore G, Perrone S, Longini M, Vezzosi P, Marzocchi B, Paffetti P, Bracci R 2002 Oxidative stress in preterm newborn at birth and on the seventh day of life. Pediatr Res 52:46-49
28. Florio P, Severi FM, Cobellis L, Danero S, Bomè A, Luisi S, Petraglia F 2002 Serum activin A and inhibin A: new clinical markers for hydatidiform mole. Cancer 94:2618-2622

29. Petraglia F, Gomez R, Luisi S, Florio P, Tolosa JE, Stomati M, Romero R 1999 Increased midtrimester amniotic fluid activin A: a risk factor for subsequent fetal death. Am J Obstet Gynecol 180:194-197

30. Manuelpillai U, Schneider-Kolsky M, Dole A, Wallace EM 2001 Activin A and activin receptors in gestational tissue from preeclamptic pregnancies. J Endocrinol 171:57-64

31. Blumenstein M, Mitchell MD, Groome NP, Keelan JA 2002 Hypoxia inhibits activin A production by term villous trophoblast in vitro. Placenta 23:735-74

32. Manuelpillai U, Schneider-Kolsky M, Thirunavukarasu P, Dole A, Waldron K, Wallace EM 2003 Effect of hypoxia on placental activin A, inhibin A and follistatin synthesis. Placenta 24:77-83

33. Bracci R, Perrone S, Buonocore G 2001 Red blood cell involvement in fetal/neonatal hypoxia. Biol Neonate 79:210-212

34. Leikin E, Verma U, Klein S, Tejani N 1996 Relationship between neonatal nucleated red blood cell counts and hypoxic-ischemic injury. Obstet Gynecol $87: 439-443$

35. Shiozaki M, Kosaka M, Eto Y 1998 Activin A: a commitment factor in erythroid differentiation. Biochem Biophys Res Commun 242:631-635

36. Shiozaki M, Sakai R, Tabuchi M, Nakamura T, Sugino K, Sugino H, Eto Y 1992 Evidence for the participation of endogenous activin A/erythroid differentiation factor in the regulation of erythropoiesis. Proc Natl Acad Sci U S A 89:15531556

37. Korst LM, Phelan JP, Ahn MO, Martin GI 1996 Nucleated red blood cells: an update on the marker for fetal asphyxia. Am J Obstet Gynecol 176:843-846

38. Maier RF, Bohme K, Dudenhausen JW, Oblade M 1993 Cord blood erythropoietin in relation to different markers of fetal hypoxia. Obstet Gynecol 81:575-580

39. Ruth V, Autti-Ramo I, Granstrom ML, Korkman M, Raivio KO 1988 Prediction of perinatal brain damage by cord plasma vasopressin, erythropoietin and hypoxanthine values. J Pediatr 113:880-885

40. Widness JA, Teramo KA, Clemons GK, Garcia JF, Cavalieri RL, Piasecki GJ, Jackson BT, Susa JB, Schwartz R 1986 Temporal response of immunoreactive erythropoietin to acute hypoxemia in fetal sheep. Pediatr Res 20:15-19 